\title{
Plymouth University goes digital for better access to textbooks
}

\author{
Linda Bennett, Proprietor Gold Leaf
}

\begin{abstract}
This paper describes the first part of a resources provision experiment that is currently taking place at Plymouth University; it involves the 'free' provision of all recommended texts to first year Psychology students in digital format, supplied via the Vital Source electronic delivery platform. The university is paying a discounted price for the service by subtracting the sum negotiated from course fees. The paper draws on student feedback collected from Dr Philip Gee, the Course Director, after the first term. It places the initiative within the wider context of changes in academia and academic publishing. It is an interim account, to be followed up with a more detailed report when the project has been completed in 2014. Broadly, initial reactions from students were favourable, though some said that they would have preferred print if it had also been available 'free' and a small minority did not like the e-book format at all.
\end{abstract}

\section{Introduction}

Print textbook sales in the UK have decreased year-on-year for more than a decade. The reasons for this are complex, and cannot be attributed to a single factor. In 2011, undergraduate students in the UK spent on average only $58 \%$ as much money on resources (such as textbooks) as they did in 2003. This figure is taken from the survey Student Information Sources in the Digital World, published by Book Marketing Limited in 2012, its first survey of UK students' attitudes to learning resources since 2003. Other findings from the BML report include: $62 \%$ of students have used an e-book 'at all'; $48 \%$ of students have downloaded e-books 'free' [note: some of these will actually have been referring to library holdings without realising it]; 38\% have borrowed e-books from the library; and $9 \%$ have themselves bought e-books. The decline in textbook sales is not just a worry for publishers; academics and politicians are also concerned that the quality of undergraduate education, and therefore the quality of the qualifications held by the UK's working graduate population, is suffering because students have not had access to the best textbook resources.

The university library is often expected to make up the shortfall in student textbook purchases, and most libraries and Higher Educational Institutions (HEls) now buy multiple print copies of core textbooks. However, no library has the resources to cater for all undergraduate textbook needs: a typical library might buy one textbook for every 10-20 students taking a particular course. Academic libraries in the UK have also been building collections of e-books for more than a decade, and some now have large collections; a majority also have 'digital-preferred' acquisitions policies. But although undergraduate use of e-monographs is widespread, the take-up of e-textbooks has been slower to develop, partly because they have been in relatively short supply. Some publishers have been reluctant to make e-textbooks available via current library purchase and subscription models, as they believe (with some justification) that this will undermine textbook sales yet further. A two year JISC project undertaken in 2008 - 2009 (see http://observatory.jiscebooks.org/), which supplied a limited number of e-textbooks 'free' to more than 120 libraries in the UK both sought to persuade publishers that a viable business model for e-textbooks could be 
achieved and - through the UK National E-Book Observatory - collected the most comprehensive body of information yet obtained and analysed on e-books usage in the Higher Education sector (Jamali et al, 2009). However, it should be noted that the etextbooks used in the study were accessible through the library only, whereas the Plymouth project described in this paper made a copy of each e-textbook available to every student individually. Therefore, some of the problems described by the 22,437 Observatory project respondents - for example, problems with Digital Rights Management [DRM], Athens authentication, etc. - will not have been encountered by the Plymouth students. The National Observatory report concludes that:

the two main advantages of e-books for students are: they were (sic) easy to access, which means that they can access them at any time anywhere, and their searchability ... The findings also show a big potential market for e-textbooks. Although students seem to favour e-books for pragmatic reasons such as avoiding going to the library, convenience of use, added features such as searching and copy and pasting are not considered to be sufficiently user-friendly. The most inhibiting feature of e-books is the difficulty of reading them from the screen (Jamali et al, 2009, 41; see also Grzeschik et al, 2011 on this topic).

However, also writing in 2009, Lam found that students' attitudes to print resources changed over time (Lam, 2009).

There has also been concern in some academic circles about the effect that using electronic textbook books may have on students' rate of reading and concentrations skills. Little research has been undertaken on this subject on e-textbooks specifically, because they are so new to the market. There is also only a small amount of published research on the use of e-books more generally within the academic context. However, there is a considerable body of work available on electronic reading rates and how to measure them. To date, much of work has been done with primary and secondary school children; but the same principles can be applied to studies of adult readers, and their reading rates measured accordingly. Drawing on these electronic reading rates, a German study of the use of e-books by a small sample of postgraduate students, carried out in 2010, concludes that "Astonishingly, and against general belief that electronic devices are less easy to use, the average reading rates for the Sony eBook Reader were the highest (162.5 wpm), followed by the laptop computer screen (140.5 wpm) and lastly the printed book (117 wpm)" (Grzeschik et al, 2011, 295296.) It should be pointed out, however, that the experiment was conducted with postgraduate library school students, who could be expected to be skilled at deploying ICT resources, even though their experience of hand-held chosen for the experiment, because it was known that these would have an effect on the reading rate. Most e-textbooks, of course, contain both.

Vital Source Technologies, Inc., an Ingram Content Group company, has enjoyed considerable success as an innovator in the United States e-textbook market, and has also been delivering e-textbooks to institutions in the UK for more than eight years. The platform is supported by a business model that is widely considered to provide a 'win-win' solution for students, lecturers and publishers. It has a relatively flexible business model that enables engagement with campuses in a variety of ways, including integration with campus Virtual Learning Environments [VLEs]. Sometimes the company works with lecturers and students directly. Lecturers are able to 'sample' e-textbooks from the Vital Source catalogue, and 
recommend them to their students. Students can then rent or purchase recommended title(s) from the platform at a preferential price.

Vital Source has gradually penetrated the UK Higher Education market. By 2012, a significant number of institutions were showing an interest in the platform, causing academic publishers to speed up their supply of textbooks to it. Further opportunities for expansion for Vital Source and its rivals have become apparent more recently as the UK higher education system itself has undergone radical and rapid change. The causes of this are complex and have their roots in many pedagogical, sociological and financial factors.

Three resulting outcomes of the changes have been of particular significance to Vital Source and its academic and publisher clients: a new emphasis from Vice-Chancellors that universities should focus on the quality of the student experience; the increase of university fees to (up to) $£ 9,000$ each year; and the UK government's directive to all universities to 'widen participation' in tertiary education, particularly by ensuring that students from poorer backgrounds are not disadvantaged, as well as by making resources available equally to distance learners (for more about inclusion and how to address it with digital resources, see: Hocking, 2010). Students now have more power to demand what they want than at any previous period in UK tertiary education; and most are saying that they don't expect to have to buy resources if they are paying several thousand pounds in fees.

\section{The Plymouth Psychology Project}

The changes in the UK higher education system have acted as a catalyst for many publishers with a significant customer base in the UK. Cengage Learning, a prominent textbook publisher, and one that has been working with Vital Source for some time, decided to formulate a new strategic approach towards the HEI community. Jeni Evans, Cengage Learning's Enterprise Solutions Manager at the time, was tasked with speaking directly to senior faculty and decision-making staff at HEl's, about how its print and electronic publications were delivered to students, and how this might be changed in the future to align with modern educational needs.

Jeni Evans worked with Dr Philip Gee, the Programme Director for Undergraduate Psychology at Plymouth University, on a ground-breaking initiative. Dr Gee was interested in supplying all first year Psychology students at Plymouth with textbooks, but was uncertain how this might be done. All the core subjects in Plymouth's Psychology programmes were targeted. Across this programme, four Cengage books had been adopted as the main texts and two from another well-known publisher had been recommended for the remaining two; and there was also a general introductory text. While a multi-publisher deal would have been Dr Gee's preferred solution, very tight time constraints led to the substitution of alternative Cengage texts because permission could not be obtained quickly from the other publisher. It also proved possible to service some of the non-core modules with Cengage texts, so the final negotiation was for a set of 12 Cengage Learning e-textbooks. Together $\mathrm{Dr}$ Gee and Vital Source explored the possibility of placing e-textbook versions of the core texts on the university library's system, but they quickly realised that this would not work, because the library and retail business models are different. Dr Gee wanted each student to have entire access to all of their texts all of the time, and to be able to read them on mobile devices; the library's e-book contract did not allow for this type of access, and it was therefore decided that the best practical solution might be to use the Vital Source platform, 
which would deliver to each participating student online, offline and mobile device access to the texts. This solution was set up as a trial, on the understanding that the university would pay the costs upfront. Plymouth's intention was to recoup the cost of the e-textbook provision direct from the students' fees.

In autumn 2011 each first year Psychology student at Plymouth was given access to his or her twelve e-textbooks through the Vital Source Bookshelf application. Access will be maintained in this way until 2014.

\section{The Plymouth Psychology Project: faculty perspective}

For Philip Gee the project stemmed from his desire to get electronic textbooks for his students. With three hundred first year students studying Psychology at Plymouth, 'we aim to point them in the right direction so that they know where to find interesting and relevant class materials'. Gee has always been a huge believer in good quality textbooks and all Psychology publishers 'are at the top of their game and all have good texts in the core subject areas'.

In the past, he had negotiated 'bundle deals with publishers. Gee encouraged students to buy bundles by making the exams open book, he explained: 'this wasn't to boost the publishers' coffers, but because I was worried about the quality of their education if they weren't getting access to the right books'. Following the announcement that Plymouth would begin to charge $£ 9,000$ in annual fees from 2012 onwards, he felt students might be even more reluctant to spend a lot of money on textbooks. Gee also felt that the traditional route to textbook adoption was no longer working: 'publishers' reps trudge round the campus and try to persuade us to change to their textbooks if we aren't using them already. If we do change, and recommend the texts to the students, who knows what percentage of the cohort will buy them?'

It was a colleague that suggested that Gee should try and negotiate a bundle for his first year students; but even with discounts, the package would have cost students several hundred pounds. Gee then started to think about promoting the use of e-books: 'I realised that one of the reasons that books were as expensive as they were was because of the students who didn't buy them, rather than those who did. What if I could secure $100 \%$ sales?'

In this model, it was not the student who was the customer, but the publisher and the platform would be working with faculty as the consumer. Gee did some research and found that the publisher Cengage had a 10 e-book bundle deal with unlimited use for an unlimited time by the student cohort. However, the titles included were not the ones that they wanted. He contacted Cengage to discuss a similar deal with different titles. They found that Cengage held the majority of the texts the programme team wanted: 'we did not set out to take all of the titles from the same publisher; but a very tight deadline resulted in a Cengage Learning-only bundle in this instance. Having now spoken to a number of publishers, I am confident that a multi-publisher deal will be possible in the future'.

Cengage senior management were very enthusiastic about the project and set up the deal just as Gee wanted. The project was funded by additional School funds at the end of the 2010-2011 academic financial year and this made Philip even more keen that the project was well managed and was delivering what the students needed. 
Working to a very tight timeframe, the e-textbook offering had to be set up very quickly. It all came together a few days prior to student induction week. Gee noted that: 'it is a tribute to Vital Source and Cengage that the technology worked almost perfectly and the content was in place. Students were e-mailed with instructions on how to access their materials, and just a handful of them misunderstood - they were able to e-mail to ask for help from Vital Source'.

Gee collected feedback from the students when they had been using the service for a week and then again at the end of the term. Feedback was received from 90 students (about $30 \%$ of the cohort). Overall, the comments were very positive. Gee is currently consulting with colleagues who would like to try out resource delivery for more courses in this way, with a view to extending across the whole university.

\section{What the Students Said}

Ninety of the first cohort of 300 students to benefit from the project provided comments. Most were positive about the results.

The students were grateful to be able to access all of their recommended texts, as one student noted: 'I am given the satisfaction of knowing that the books are all in one place and accessible'.

Not only were the books accessible, there was also the convenience of $24 / 7$ access, and of not having to carry heavy books around the campus.

I believe that these books are a great source for the course. They are very useful if you are at home and want to look something over from a lecture; it means you can easily do this from your laptop. It also saves having to carry big heavy books around.

This can be particularly beneficial for non-traditional students:

I am a single mum with three children - they are all under five, thus staying at the university after lectures was impossible, as well as going to the library to borrow books.

Also important for the students was the ease of navigation, note taking and searching that the e-books offered, as these quotes show:

Being able to navigate to what I want easily using the search box has been the best part for me.

Far simpler than desperately scanning through a textbook!

Extremely easy to make notes, which can be edited, deleted or shared.

A few students said they would have bought all the titles themselves; many would not have bought more than one; and some would not have bought any due to the expense:

If I did not get the e-books, I would not have a copy of all the core books, as I would not be able to afford them.

Overall, the students very happy to receive the e-books 'free' as part of their university fees. 
E-books are great: you saved us huge amounts of money ...

And, as one student noted, it certainly helped with independent study:

It really gives you no excuse to not be prepared for lectures.

Ninety of the first cohort of 300 students to benefit from the project provided comments. Most were positive about the results.

The students were grateful to be able to access all of their recommended texts, as one student noted: 'I am given the satisfaction of knowing that the books are all in one place and accessible'.

Not only were the books accessible, there was also the convenience of $24 / 7$ access, and of not having to carry heavy books around the campus.

I believe that these books are a great source for the course. They are very useful if you are at home and want to look something over from a lecture; it means you can easily do this from your laptop. It also saves having to carry big heavy books around.

This can be particularly beneficial for non-traditional students:

I am a single mum with three children - they are all under five, thus staying at the university after lectures was impossible, as well as going to the library to borrow books.

Also important for the students was the ease of navigation, note taking and searching that the e-books offered, as these quotes show:

Being able to navigate to what I want easily using the search box has been the best part for me.

Far simpler than desperately scanning through a textbook!

Extremely easy to make notes, which can be edited, deleted or shared.

A few students said they would have bought all the titles themselves; many would not have bought more than one; and some would not have bought any due to the expense:

If I did not get the e-books, I would not have a copy of all the core books, as I would not be able to afford them.

Overall, the students very happy to receive the e-books 'free' as part of their university fees.

E-books are great: you saved us huge amounts of money ...

And, as one student noted, it certainly helped with independent study: 'it really gives you no excuse to not be prepared for lectures'.

However, not all of the students liked using the e-textbooks. $36 \%$ of respondents said that they preferred studying from print, even to the extent of being prepared to buy the print version of titles that they had received free in electronic format. Some students remarked 
that straightforward digitisation of the print text results in a publication was not always easy to navigate electronically. Other problems they noted included:

Not pleasant reading from a screen / gives me a headache.

Interferes with concentration over long periods of time.

Some also experienced various technical problems. These problems could often be attributable to the fact that the student was working on an old PC or one of the less wellknown proprietary e-readers. A final issue was that some students found it less convenient to carry a device with them than to carry books.

\section{Necessity of taking laptop / gadget everywhere}

\section{Conclusion}

The Plymouth experiment is ongoing. More information will be gathered about how Psychology students respond to the 'free' e-book collection over the course of its four year schedule. This will include the monitoring of the standard of the students' work and examination results, as well as student satisfaction with electronic resources, as the first cohort to engage with the project progresses through the university. The preliminary evidence that has been gathered is encouraging. Almost two thirds of the students who volunteered comments indicated that they did not have problems with using electronic texts, and some preferred them (though for a variety of reasons, not all of them pedagogical). That the e-textbook collection was provided as part of the course fees appealed to almost all of the students, and is in itself an effective way of helping to address the inclusion issue. Students' questioning of whether straightforward digitised versions of print texts are fit-forpurpose as academic learning and teaching methods change sends a clear message to publishers which they will fail to take seriously at their peril. By engaging with collaborative projects of this kind, academics, students, publishers and aggregators together are conducting 'action research' into the nature and format that learning resources of the future should take.

\section{References}

Book Marketing Limited. "Student information sources in the digital world". Survey published in March 2012. London: Bowker Market Research.

Grzeschik, K., Kruppa, Y., Marti, D. and Donner, P. (2011). 'Reading in 2110 - reading behavior and reading devices: a case study', The Electronic Library, 29(3), 288 - 302. Available at: 10.1108/02640471111141052 (accessed 17 May 2012).

Hockings, C. (2010) Inclusive learning and Teaching: Research Synthesis. York: Higher Education Academy.

Jamali, H.R, Nicholas, D. and Rowlands, I. (2009). 'Scholarly e-books: the views of 16,000 academics: Results from the JISC National E-Book Observatory', Aslib Proceedings, 61(1), 33-47. Available at: 10.1108/00012530910932276 (accessed 17 May 2012).

Lam, P.; Lam, S. L.; Lam, J.; and McNaught, C.(2009). 'Usability and usefulness of eBooks on PPCs: How students' opinions vary over time', Australasian Journal of Educational Technology, 25(1), 30-44. 


\section{Acknowledgements}

I am indebted to Dr Philip Gee of Plymouth University, who has been extremely generous with his time and by sharing the research he undertook on student feedback. I'd also like to thank Nick Candy, Senior Lecturer in Publishing at University College London, Dr Mark Kerrigan, Senior Lecturer in Education, Physiology and Anatomy at the University of Greenwich and Elspeth Williams, Learning and Teaching Fellow at the University of the West of England for advice and for their help in supplying articles on electronic learning and teaching. I should like to thank them all very sincerely.

\section{Author Biography}

Linda Bennett is the proprietor of Gold Leaf, a small consultancy which advises publishers, academics, librarians and others in the publishing and academic communities on electronic publishing, especially in the academic field. She was formerly Business Development Director at Waterstone's and MBA Course Director at the University of Huddersfield. She is a Visiting Research Fellow at Huddersfield University, Manchester Metropolitan University and the University of the West of England. 